\title{
sciendo
}

\section{Media channels impact in brand indicators in Romania}

\author{
Cristina BURLACIOIU \\ Bucharest University of Economic Studies, Bucharest, Romania \\ cristinaburlacioiu@yahoo.com \\ Cristina BOBOC \\ Bucharest University of Economic Studies, Bucharest, Romania \\ cristina.boboc@csie.ase.ro \\ Constantin MITRUȚ \\ Bucharest University of Economic Studies, Bucharest, Romania \\ cmitrut@ase.ro \\ Ioan SIMU \\ University of Bucharest, Bucharest, Romania \\ ioan simu@mercury.ro
}

\begin{abstract}
Finding the main influencers in brand indicators is a challenge for every marketing manager and researchers working in the branding investments area. How much to invest, which is the proper media channel mix or what is the influence of brand heritage are the questions of interest and which the paper responds to. Therefore, this paper is aiming to analyze the brand performance indicators in 2018 (awareness, trial and usage) for over 700 brands in Romania based on their investment on each media channel for 2014-2018 period and 2014 brand indicators. As for characterization of media investment 47 variables were retained, principal component analysis was used for reducing factors of influence. Thus, four main components were retrieved: media investment in absolute measures, main and second proportion in terms of media channel mix, and qualitative aspects of the brand. In conclusion, some multivariate regressions were built for identifying impact on each 2018 brand indicator using the four principal components and 2014 levels of the brand indicators.
\end{abstract}

Keywords: Principal Component Analysis, Regression model, media channels investment, brand performance, Romania.

\section{Introduction}

The companies need to create a good overview of their marketing performance, run scenarios, and continuous adapt ad strategies in order to have the best brand position on the market. Usually, marketers work with traditional analytics measurement methods, which are revised a few times a year to correlate sales with a few dozen variables (Nichols, 2013), mostly related to media channels budgets and sometimes they do not know which measure is a better fit for their brand.

This paper approaches media channels investments during considerable period of time (2014-2018) for consistent number of brands in Romania (over 700 brands), their qualitative aspects regarding qualitative perception and ad appeal and their impact on brand 
indicators: brand and ad awareness, trial and usage.

\section{Literature review}

Researchers usually study media investment impact for only one brand, as the access might permit. For example, Sciarrino et al. (2019) use Using Cotton Incorporated as a case study, and presents a customer journey model, or integrated approach, with brand attachment as a proxy for the intermediate effect. The resulting model is an objective approach to link POE media to demand and describe contribution and efficiency in terms of both revenue and brand attachment. This approach enabled data-driven insights that were used to evaluate and optimize Cotton Incorporated's entire POE marketing communications efforts more accurately than traditional methods. Gallego et al. (2017) settled a data-driven method for the supervision of a company advertising investments, also. Primary, using the company's advertising expenditures, they suggest a design of the Nerlove-Arrow model via a Bayesian structural time series to forecast global sales variable which also incorporates information from the external environment (climate, economical situation and special events). They reached a model with low predictive errors while upholding interpretability and can be built in a modular manner, which provides great flexibility to adjust it to different business situations. The important outcome of the model is that it can be used as a decision sustenance system at management level, supporting the process of setting the advertising budgets.

More brands - but in only one domain (beauty care) - were studied by Dens et al. (2018). They have recently proposed an original methodology, mixture-amount modeling (MAM) that explores cross-media advertising synergy based on consumers' media usage. MAM permits to derive optimal media mixes that can be altered for each type of media users. The researchers have investigated 46,852 responses to 92 beauty care advertising campaigns using 10,972 respondents from 4 countries: Netherlands, Belgium, Finland, and Hungary. They have described the effect of mixed media channels like print, television, and online, namely "how intensively they use media overall and the relative proportion of each individual medium on their campaign-evoked brand interest, perceived brand equity, and purchase intention for advertised brands". The conclusions have identified that different patterns of consumer media usage may trigger different reactions to advertising stimuli.

Recently, Dawes et al. (2018) have investigated the same area, too, specifically the impact of regression analysis in exploring the advertising and media channels decisionmaking. They concluded that econometrics need an extensive experimental data on main variables, across varied conditions in order to reach valid and consistent forecasting models. Their research canvasses different evidence-based methodologies that have been revealed to be valuable for prediction area. The methods include media and copy tests, analyses of individual level single source data, and structured expert judgment.

Furthermore, for studying the conversion to sale rate, Nisar \& Yeung (2017) were investigating digital advertising campaigns often launched across multiple online channels, like search, display advertisements, social media, mobile, video, and e-mail. These channels could influence the customer purchase decisions or his sign up to an advertised service considering different levels of exposure to advertisement impressions. (Fulgoni, 2016; Yang and Ghose, 2010). In order to scale the effectiveness of these kind of advertising campaigns, the attribution process was analyzed, namely which media channels or advertising formats have influenced the buying conversion rate. An enhanced approach of the attribution model like the one presented in authors' article, or allocating conversion impact to the different 
relevant channels, can support a consistent number of researches and business purposes. Moreover, marketing managers may use wisely such attribution models to understand the effect of advertisements on consumer behavior and specially to improve their advertising campaigns for efficiency reasons.

Bass et al. (2007) set up a model that equally reflects the influence of wear out as well as that of forgetting in the framework of an advertising campaign that uses five different advertising themes. They quantify the differential wearout impacts across the different themes of advertising and examine the interaction effects between the different themes using a Bayesian dynamic linear model (DLM). The importance of this model is still on the same area of optimizing the allocation of different advertising resources as well as better scheduling process as it reveals "how the response model parameters can be used to improve the effectiveness of advertising budget allocation across different themes".

\section{Methodology}

This research analyzes the data based on two-waves of survey conducted by the research agency in Romania - Mercury Research and exhaustive media investment database generously provided by Mediacom.

The survey was made up on a representative sample at population 18+ years old urban level which includes up to 782 Romanian brands clustered in several categories (FMCG - food, beverage, care and cleaning, shops - including online stores, electronics, and health services). The main indicators collected by the two-waves survey are related to brand and advertising funnel: brand awareness, trial, usage and how much the ad was appreciated.

Moreover, the monthly advertising investments on main media channels (TV, internet, print, radio) were added. The two periods considered were 2011 to 2014 and 2H 2017 - 1H 2018 further named within the article as last 12 months or last year.

\section{Results and discussions}

Considering the fact that media channel and especially the weight or predominance of one channel in total media portfolio investment might have an impact on brand indicators, the brands are clustered using this media channels weight into 7 categories:

- No investment (No invest) for all the brands that have total media investment last year by any channel $=0$

- TV predominant (TV Pred) for all the brand that invested on TV more than $60 \%$ of total media budget spent on all media channels

- Online predominant (O Pred) for all the brand that invested on online more than $50 \%$ of total media budget spent on all media channels

- Radio predominant (R Pred) for all the brand that invested on radio more than $50 \%$ of total media budget spent on all media channels

- Print predominant (P Pred) for all the brand that invested on print more than $50 \%$ of total media budget spent on all media channels

- Out of home predominant (OOH Pred) for all the brand that invested on $\mathrm{OOH}$ more than $50 \%$ of total media budget spent on all media channels

- All the rest for any other mix channels (Oth_mix).

All brand indicators for 2018 (brand awareness, ad awareness, trial, usage, perceived quality for brand and ad appeal) were analyzed through One way ANOVA considering their 
mean for 2018 for each of the seven categories based on the profile of their media channels mix shown above (Table 1).

Table 1. Brands variables measured for media channels predominance category

\begin{tabular}{|c|c|c|c|c|c|c|c|c|c|}
\hline Variable & Indicator & $\begin{array}{c}\text { No } \\
\text { invest }\end{array}$ & $\begin{array}{c}\text { TV } \\
\text { Pred }\end{array}$ & 0 Pred & R Pred & P Pred & $\begin{array}{l}\text { OOH } \\
\text { Pred }\end{array}$ & Oth_mix & Total \\
\hline \multirow{3}{*}{$\begin{array}{c}\text { Brand } \\
\text { awareness }\end{array}$} & No. & 398 & 256 & 34 & 15 & 23 & 18 & 38 & 782 \\
\hline & Mean & 0.27 & 0.70 & 0.50 & 0.57 & 0.35 & 0.54 & 0.75 & 0.46 \\
\hline & Std.dev. & 0.25 & 0.20 & 0.27 & 0.19 & 0.27 & 0.30 & 0.21 & 0.31 \\
\hline \multirow{3}{*}{$\begin{array}{c}\text { Ad } \\
\text { awareness }\end{array}$} & No. & 396 & 256 & 33 & 15 & 23 & 18 & 38 & 779 \\
\hline & Mean & 0.03 & 0.25 & 0.11 & 0.09 & 0.05 & 0.14 & 0.31 & 0.12 \\
\hline & Std.dev. & 0.05 & 0.14 & 0.11 & 0.07 & 0.06 & 0.14 & 0.20 & 0.15 \\
\hline \multirow{3}{*}{ Trial } & No. & 396 & 256 & 34 & 15 & 23 & 18 & 38 & 780 \\
\hline & Mean & 0.12 & 0.43 & 0.24 & 0.23 & 0.14 & 0.26 & 0.45 & 0.25 \\
\hline & Std.dev. & 0.16 & 0.23 & 0.23 & 0.16 & 0.15 & 0.26 & 0.25 & 0.24 \\
\hline \multirow{3}{*}{ Usage } & No. & 384 & 256 & 33 & 15 & 23 & 16 & 38 & 765 \\
\hline & Mean & 0.03 & 0.15 & 0.07 & 0.06 & 0.04 & 0.09 & 0.19 & 0.08 \\
\hline & Std.dev. & 0.05 & 0.12 & 0.07 & 0.07 & 0.05 & 0.11 & 0.17 & 0.11 \\
\hline \multirow{3}{*}{$\begin{array}{c}\text { Quality } \\
\text { perceived }\end{array}$} & No. & 393 & 256 & 34 & 15 & 23 & 18 & 38 & 777 \\
\hline & Mean & 4.02 & 4.09 & 4.09 & 3.92 & 4.24 & 4.02 & 3.99 & 4.05 \\
\hline & Std.dev. & 0.44 & 0.30 & 0.39 & 0.41 & 0.34 & 0.29 & 0.27 & 0.38 \\
\hline \multirow{3}{*}{ Ad appeal } & No. & 393 & 256 & 33 & 15 & 23 & 18 & 38 & 776 \\
\hline & Mean & 4.14 & 3.91 & 4.08 & 3.85 & 3.99 & 3.81 & 3.82 & 4.03 \\
\hline & Std.dev. & 0.45 & 0.18 & 0.32 & 0.21 & 0.32 & 0.30 & 0.16 & 0.38 \\
\hline
\end{tabular}

In terms of brand awareness, no investment in advertising within 12 months implies a brand awareness for this category of brand almost 3 times lower than a brand awareness of the brands that invest on TV or mix media channels and half of the performance of brand investing in predominant radio or online. Even lower results might be observed for ad awareness for this category of brand with no investment - 4 times lower than the average for all 779 brands measured for this brand indicator. No investment for a year has a negative effect also on the bottom of the funnel indicators, trial and usage for the brands that didn't have any investment on media being at half versus the total mean.

Surprisingly, no investment category has a higher mean for the ad appeal indicator. This might mean that not seeing any ads recently might imply that the people recall the brand as having appealing advertising in the past, while all the negative part of the ads disappeared without a trace. On the other words, current advertising seems to be annoying at the present, but in time, the effect might be reversed.

TV predominance and all the other media channels mixes that do not involve any channel predominance bring to the brand higher performances in terms of ad awareness, trial and usage than the other categories of media investment (radio, print, out of home, but mostly the hero channels: online).

Tukey test has revealed the statistically significant differences of each category from another. 
Table 2. Mean differences - Tukey test for brand awareness

\begin{tabular}{|l|r|r|r|r|r|r|}
\hline Indicator & TV Pred & O Pred & R Pred & P Pred & OOH Pred & Oth_mix \\
\hline No invest & $-0.43^{*}$ & $-0.23^{*}$ & $-0.30^{*}$ & -0.08 & $-0.27^{*}$ & $-0.48^{*}$ \\
\hline TV Pred & & $0.20^{*}$ & 0.13 & $0.35^{*}$ & $0.16^{*}$ & -0.05 \\
\hline O Pred & & & -0.07 & 0.15 & -0.04 & $-0.25^{*}$ \\
\hline R Pred & & & & 0.22 & 0.03 & -0.18 \\
\hline P Pred & & & & & -0.19 & $-0.40^{*}$ \\
\hline OOH Pred & & & & & & $0.21^{*}$ \\
\hline
\end{tabular}

Source: Authors' own research on SAS Enterprise Guide

The brands that invest significantly in print are having extremely poor results in terms of brand awareness as the brands that haven't invest anything on media for the last 12 months. All other categories have consistently higher results than No Invest. Oth_mix, TV Pred categories are having significantly good results versus all other categories except $\mathrm{R}$ Pred. That means that radio predominance might attract rather good results for brand awareness at lower expense than TV Pred or Oth_mix. Online and $\mathrm{OOH}$ predominant categories succeeded to have only an average value of brand awareness, higher significantly only compared to No invest and significantly lower than TV Pred and Oth_mix.

Table 3. Mean differences - Tukey test for ad awareness

\begin{tabular}{|l|r|r|r|r|r|r|}
\hline Indicator & TV Pred & O Pred & R Pred & P Pred & OOH Pred & Oth_mix \\
\hline No invest & $-0.22^{*}$ & $-0.07^{*}$ & -0.06 & -0.02 & $-0.11^{*}$ & $-0.28^{*}$ \\
\hline TV Pred & & $0.14^{*}$ & $0.15^{*}$ & $0.20^{*}$ & $0.11^{*}$ & $-0.06^{*}$ \\
\hline O Pred & & & 0.01 & 0.06 & -0.04 & $-0.21^{*}$ \\
\hline R Pred & & & & 0.04 & -0.05 & $-0.22^{*}$ \\
\hline P Pred & & & & & -0.09 & $-0.26^{*}$ \\
\hline OOH Pred & & & & & & $0.17^{*}$ \\
\hline
\end{tabular}

Source: Authors' own research on SAS Enterprise Guide

In terms of ad awareness, radio performance seems to be as low as print and no investment categories. TV and Oth_mix are overpassing significantly all other categories. Oth_mix is the best solution if one company is searching for ad awareness, the mean value for ad awareness being significantly higher than all the other categories, better even than TV Pred. Actually, this is the unique brand performance indicator that Oth_mix is overpassing significantly TV Pred.

Table 4. Mean differences - Tukey test for trial

\begin{tabular}{|l|r|r|r|r|r|r|}
\hline Indicator & TV Pred & O Pred & R Pred & P Pred & OOH Pred & Oth_mix \\
\hline No invest & $-0.31^{*}$ & $-0.12^{*}$ & -0.10 & -0.02 & -0.14 & $-0.33^{*}$ \\
\hline TV Pred & & $0.19^{*}$ & $0.21^{*}$ & $0.29^{*}$ & $0.17^{*}$ & -0.02 \\
\hline O Pred & & & 0.01 & 0.10 & -0.02 & $-0.21^{*}$ \\
\hline R Pred & & & & 0.09 & -0.03 & $-0.22^{*}$ \\
\hline P Pred & & & & & -0.12 & $-0.31^{*}$ \\
\hline OOH Pred & & & & & & $0.19^{*}$ \\
\hline
\end{tabular}

Source: Authors' own research on SAS Enterprise Guide 
Even if the brand trial average value for R Pred, P Pred and OOH Pred is doubled than No invest, the difference is not significant. Thus, it could be said that the major investment in radio, print or $\mathrm{OOH}$ didn't worth in terms of attracting brand interest and start using it.

Table 5. Mean differences - Tukey test for usage

\begin{tabular}{|l|r|r|r|r|r|r|}
\hline Indicator & TV Pred & O Pred & R Pred & P Pred & OOH Pred & Oth_mix \\
\hline No invest & $-0.12^{*}$ & -0.04 & -0.03 & -0.01 & -0.06 & $-0.16^{*}$ \\
\hline TV Pred & & $0.08^{*}$ & $0.09^{*}$ & $0.11^{*}$ & 0.06 & -0.04 \\
\hline O Pred & & & 0.01 & 0.03 & -0.02 & $-0.12^{*}$ \\
\hline R Pred & & & & 0.02 & -0.03 & $-0.13^{*}$ \\
\hline P Pred & & & & & -0.05 & $-0.15^{*}$ \\
\hline OOH Pred & & & & & & $0.10^{*}$ \\
\hline
\end{tabular}

Source: Authors' own research on SAS Enterprise Guide

For usage, the differences between categories are exactly the same as in case of trial, except for online predominant category that didn't succeed to have significantly higher results versus No invest as in previous cases. Thus, in order to increase sales it is not an option to be present only on online and TV or any other wise mix is needed.

Table 6. Mean differences - Tukey test for ad appeal

\begin{tabular}{|l|r|r|r|r|r|r|}
\hline Indicator & TV Pred & O Pred & R Pred & P Pred & OOH Pred & Oth_mix \\
\hline No invest & $0.24^{*}$ & 0.07 & $0.29^{*}$ & 0.15 & $0.34^{*}$ & $0.32^{*}$ \\
\hline TV Pred & & -0.17 & 0.05 & -0.09 & 0.10 & 0.08 \\
\hline O Pred & & & 0.22 & 0.08 & 0.27 & $0.25^{*}$ \\
\hline R Pred & & & & -0.14 & 0.05 & 0.03 \\
\hline P Pred & & & & & 0.19 & 0.17 \\
\hline Oth_mix & & & & & & 0.02 \\
\hline
\end{tabular}

Source: Authors' own research on SAS Enterprise Guide

Even if the predominant online advertising doesn't attract the maximum interest on sales, the analysis revealed that at least the advertising is appealing for the customers, the mean for 0 Pred being significantly different than the mean for Oth_mix.

For perceived quality no significance at $95 \%$ confidence was retrieved based on Tukey test.

In order to determine the patterns of brands based on their advertising investment and appeal or perceived quality at present but also in evolution, principal component analysis (PCA) will be used. PCA is the technique used to reduce multidimensional data sets to lower dimensions, when all the variables used are quantitative. It is mathematically defined as an orthogonal linear transformation that projects the data to a new coordinate system (which is made by principal components) in order to obtain the greatest variance explained by this projection of the data. Using this methodology, the following variables in table 6 are analyzed:

\section{Table 6. Rotated Component Matrix}




\begin{tabular}{|c|c|c|c|c|}
\hline & \multicolumn{4}{|c|}{ Component } \\
\hline & 1 & 2 & 3 & 4 \\
\hline Last $12 \mathrm{~m}$ All & 0.979 & -0.100 & 0.018 & -0.036 \\
\hline 1H18 ALL & 0.972 & -0.125 & 0.022 & -0.036 \\
\hline 1H18 All wo $\mathrm{OOH}$ & 0.961 & -0.146 & -0.016 & -0.034 \\
\hline 2H14 All wo $\mathrm{OOH}$ & 0.953 & -0.028 & -0.060 & -0.023 \\
\hline Last 12 m Online & 0.915 & 0.070 & -0.059 & -0.018 \\
\hline Last $12 \mathrm{~m}$ TV & 0.910 & -0.221 & -0.062 & -0.054 \\
\hline 2H14 TV & 0.902 & -0.066 & -0.086 & -0.044 \\
\hline Last $12 \mathrm{~m}$ Print & 0.894 & 0.071 & -0.041 & 0.017 \\
\hline Last $12 \mathrm{~m} \mathrm{OOH}$ & 0.744 & 0.047 & 0.248 & -0.041 \\
\hline 2H14 Online & 0.718 & 0.101 & -0.116 & -0.010 \\
\hline 2H14 Radio & 0.674 & -0.116 & 0.197 & 0.043 \\
\hline Last 12 m Radio & 0.662 & -0.148 & 0.376 & 0.041 \\
\hline 2H14 Print & 0.648 & 0.043 & 0.000 & 0.025 \\
\hline$\%$ TV in last 12 months & -0.016 & -0.815 & -0.399 & -0.197 \\
\hline TV Pred & -0.123 & -0.769 & -0.479 & -0.182 \\
\hline O Pred & -0.049 & 0.651 & 0.034 & -0.166 \\
\hline$\%$ Online in last $12 \mathrm{~m}$ & 0.117 & 0.596 & 0.065 & -0.216 \\
\hline No invest & -0.127 & 0.375 & 0.025 & 0.123 \\
\hline 2018 Ad Appeal & -0.084 & 0.359 & -0.264 & 0.149 \\
\hline delta $1 \mathrm{H} 18$ vs $2 \mathrm{H} 14$ & 0.192 & -0.263 & 0.084 & -0.029 \\
\hline$\%$ Radio in last $12 \mathrm{~m}$ & 0.043 & -0.097 & 0.761 & 0.053 \\
\hline \% OOH in last $12 \mathrm{~m}$ & 0.147 & 0.182 & 0.581 & -0.095 \\
\hline Radio Pred & -0.085 & -0.052 & 0.529 & 0.039 \\
\hline Oth_mix & 0.416 & 0.072 & 0.427 & 0.009 \\
\hline $\mathrm{OOH}$ Pred & 0.015 & 0.136 & 0.364 & -0.077 \\
\hline 2018 Perceived Quality & -0.010 & -0.028 & -0.351 & -0.022 \\
\hline$\% 1 \mathrm{H} 18$ vs $2 \mathrm{H} 14$ & -0.035 & 0.012 & 0.190 & 0.030 \\
\hline Delta Ad Appeal & -0.038 & 0.137 & -0.048 & 0.789 \\
\hline 2014 Ad Appeal & -0.006 & 0.052 & -0.096 & -0.787 \\
\hline Print Pred & -0.014 & 0.308 & -0.278 & 0.559 \\
\hline$\%$ Print in last 12 months & 0.007 & 0.373 & -0.244 & 0.544 \\
\hline Delta Perceived Quality & -0.006 & -0.173 & 0.199 & 0.546 \\
\hline 2014 Perceived Quality & -0.002 & 0.138 & -0.433 & -0.512 \\
\hline
\end{tabular}

Source: Authors' own research on SPSS. Extraction Method: Principal Component Analysis. Rotation Method: Varimax with Kaiser Normalization. Rotation converged in 6 iterations.

By applying this method, data projection on the first four principal components preserves $54.6 \%$ of the total inertia $(29.6 \%$ for the first axis, $10.6 \%$ for the second axis, $7.5 \%$ for the third axis and $6.9 \%$ for the fourth axis).

First axis is represented only by absolute indicators related to the size of advertising, so could be called absolute media investment. It contains all the variables related to media investment in any of the periods monitored - 2H 2014, 1H 2018, Last 12 months (2H 2017+ $1 \mathrm{H} \mathrm{2018)} \mathrm{-} \mathrm{for} \mathrm{any} \mathrm{of} \mathrm{the} \mathrm{media} \mathrm{channels} \mathrm{(TV,} \mathrm{online,} \mathrm{radio,} \mathrm{print,} \mathrm{OOH}$ or total).

The second axis is related to relative sizes of media investment through main channels: TV and online (TV or online weight of total investment) or particularities due to no investment (no existence at all of media investment within last 12 months or higher ad appeal generated by the absence of brands on media market). Therefore the axis could be called the main proportions. TV related variables are on negative side, while all other variables included shown on Table 6 are on positive side.

The third axis contains also relative indicators related to media channels mix, this time 
for the rest of channels: radio, out of home, their predominance in total budget or any other mix in which no channel is predominant, all on the positive side. On negative side there is only one variable related to perceived brand quality in 2018 , namely variable which seems to not vary based on category of media channels predominance. Considering all these, the axis could be defined as secondary proportions.

The fourth axis is mainly related to qualitative aspects of brand: ad appeal and perceived quality of the brand - both of them measured in 2014 and absolute increase in 2018 versus 2014.

Performance brand indicators were measured in two moments in time for 2014 and 2018 on representative sample of urban population with age 18+. Indicators of interest are the ones that are related to marketing sales funnel, namely:

- Top of the funnel: awareness measured trough brand and ad assisted awareness

- Middle of the funnel: interest measured trough brand trial

- Bottom of the funnel: purchase measured trough brand usage

Those eight indicators are correlated as per correlation matrix shown in table 7.

Table 7. Correlation Matrix

\begin{tabular}{|c|r|r|r|r|r|r|r|r|}
\hline & $\begin{array}{c}2014 \text { Brand } \\
\text { Awareness }\end{array}$ & $\begin{array}{c}2014 \\
\text { Trial }\end{array}$ & $\begin{array}{c}2014 \\
\text { Usage }\end{array}$ & $\begin{array}{c}2014 \text { Ad } \\
\text { Awareness }\end{array}$ & $\begin{array}{c}2018 \text { Brand } \\
\text { Awareness }\end{array}$ & $\begin{array}{c}2018 \\
\text { Trial }\end{array}$ & $\begin{array}{c}2018 \\
\text { Usage }\end{array}$ & $\begin{array}{c}2018 \text { Ad } \\
\text { Awareness }\end{array}$ \\
\hline $\begin{array}{c}2014 \\
\text { Brand } \\
\text { Awareness }\end{array}$ & 1 & $0.894^{* *}$ & $0.709^{* *}$ & $0.776^{* *}$ & $\mathbf{0 . 9 6 6}^{* *}$ & $0.876^{* *}$ & $0.692^{* *}$ & $0.729^{* *}$ \\
\hline 2014 Trial & $0.894^{* *}$ & 1 & $0.841^{* *}$ & $0.783^{* *}$ & $0.861^{* *}$ & $\mathbf{0 . 9 7 1}^{* *}$ & $0.819^{* *}$ & $0.739^{* *}$ \\
\hline $\begin{array}{c}2014 \\
\text { Usage }\end{array}$ & $0.709^{* *}$ & $0.841^{* *}$ & 1 & $0.779^{* *}$ & $0.692^{* *}$ & $0.825^{* *}$ & $\mathbf{0 . 9 3 3}^{*}$ & $0.737^{* *}$ \\
\hline $\begin{array}{c}2014 \text { Ad } \\
\text { Awareness }\end{array}$ & $0.776^{* *}$ & $0.783^{* *}$ & $0.779^{* *}$ & 1 & $0.763^{* *}$ & $0.786^{* *}$ & $0.768^{* *}$ & $\mathbf{0 . 9 2 2}^{* *}$ \\
\hline $\begin{array}{c}\text { 2018 } \\
\text { Brand } \\
\text { Awareness }\end{array}$ & $0.966^{* *}$ & $0.861^{* *}$ & $0.692^{* *}$ & $0.763^{* *}$ & 1 & $0.886^{* *}$ & $0.715^{* *}$ & $0.774^{* *}$ \\
\hline \begin{tabular}{c}
2018 Trial \\
\hline $\begin{array}{c}2018 \\
\text { Usage }\end{array}$
\end{tabular} & $0.876^{* *}$ & $0.971^{* *}$ & $0.825^{* *}$ & $0.786^{* *}$ & $0.886^{* *}$ & 1 & $0.862^{* *}$ & $0.789^{* *}$ \\
\hline $\begin{array}{c}2018 \text { Ad } \\
\text { Awareness }\end{array}$ & $0.692^{* *}$ & $0.819^{* *}$ & $0.933^{* *}$ & $0.768^{* *}$ & $0.715^{* *}$ & $0.862^{* *}$ & 1 & $0.814^{* *}$ \\
\hline
\end{tabular}

Source: Authors' own research on SPSS. Note: ${ }^{* *}$ Correlation is significant at the 0.01 level $(2$-tailed)

In order to see the influence of 2014 inheritance of brand indicators and media investment pattern into 2018 brand performance indicators, multiple linear regressions (MLR) were conducted on forward/stepwise selection method. MLR is the statistical technique that uses explanatory variables to predict the outcome of a response variable. The goal of MLR is to model the linear relationship between the explanatory (independent) variables and response (dependent) variable.

For determining the impact on 2018 Trial, the 2014 brand awareness and the four principal components were considered in the multilinear regression model. 
Table 8. Coefficients

\begin{tabular}{|c|c|c|c|c|c|c|c|c|}
\hline \multirow{2}{*}{\multicolumn{2}{|c|}{ Model }} & \multicolumn{2}{|c|}{$\begin{array}{l}\text { Unstandardized } \\
\text { Coefficients }\end{array}$} & \multirow{2}{*}{$\begin{array}{l}\text { Standardized } \\
\text { Coefficients } \\
\text { Beta }\end{array}$} & \multirow[t]{2}{*}{$\mathrm{t}$} & \multirow[t]{2}{*}{ Sig. } & \multicolumn{2}{|c|}{ Collinearity Statistics } \\
\hline & & $\mathrm{B}$ & Std. Error & & & & Tolerance & VIF \\
\hline \multirow[t]{2}{*}{1} & (Constant) & -12.175 & 2.395 & & -5.084 & .000 & & \\
\hline & $\begin{array}{l}2014 \text { Brand } \\
\text { Awareness } \\
\text { (Assisted) }\end{array}$ & .788 & .034 & .806 & 23.518 & .000 & 1.000 & 1.000 \\
\hline \multirow[t]{3}{*}{2} & (Constant) & -10.442 & 2.466 & & -4.235 & .000 & & \\
\hline & $\begin{array}{l}2014 \text { Brand } \\
\text { Awareness } \\
\text { (Assisted) }\end{array}$ & .762 & .035 & .780 & 21.979 & .000 & .916 & 1.091 \\
\hline & Component 2 & -2.219 & .861 & -.091 & -2.577 & .010 & .916 & 1.091 \\
\hline \multirow[t]{4}{*}{3} & (Constant) & -9.159 & 2.534 & & -3.615 & .000 & & \\
\hline & $\begin{array}{l}2014 \text { Brand } \\
\text { Awareness } \\
\text { (Assisted) }\end{array}$ & .743 & .036 & .760 & 20.773 & .000 & .852 & 1.173 \\
\hline & Component 2 & -2.357 & .859 & -.097 & -2.742 & .006 & .911 & 1.098 \\
\hline & Component 1 & 1.722 & .850 & .071 & 2.025 & .044 & .930 & 1.075 \\
\hline
\end{tabular}

Source: Authors' own research on SPSS. Dependent variable: 2018 Trial

The best model has $\mathrm{R}^{2}=0.662$ and retains 2014 brand awareness, component 2 - main proportions of media investment and component 1- absolute media investment.

For determining the impact on 2018 Usage, the 2014 Trial and the four principal components were considered in the linear regression model.

Table 9. Coefficients

\begin{tabular}{|c|c|c|c|c|c|c|c|c|}
\hline \multirow{2}{*}{\multicolumn{2}{|c|}{ Model }} & \multicolumn{2}{|c|}{$\begin{array}{l}\text { Unstandardized } \\
\text { Coefficients }\end{array}$} & \multirow{2}{*}{$\begin{array}{l}\text { Standardized } \\
\text { Coefficients } \\
\text { Beta }\end{array}$} & \multirow[t]{2}{*}{$\mathrm{t}$} & \multirow[t]{2}{*}{ Sig. } & \multirow{2}{*}{$\begin{array}{l}\text { Collinearity } \\
\text { Statistics } \\
\text { Tolerance }\end{array}$} & \multirow[b]{2}{*}{ VIF } \\
\hline & & $\mathrm{B}$ & Std. Error & & & & & \\
\hline \multirow[t]{2}{*}{1} & (Constant) & -1.764 & .864 & & -2.042 & .042 & & \\
\hline & 2014 Trial & .400 & .018 & .783 & 21.709 & .000 & 1.000 & 1.000 \\
\hline \multirow[t]{3}{*}{2} & (Constant) & -1.048 & .873 & & -1.201 & .231 & & \\
\hline & 2014 Trial & .382 & .019 & .747 & 20.275 & .000 & .923 & 1.084 \\
\hline & Component 1 & 1.663 & .479 & .128 & 3.473 & .001 & .923 & 1.084 \\
\hline
\end{tabular}

Source: Authors' own research on SPSS. Dependent variable: 2018 Usage

The best model has $\mathrm{R}^{2}=0.628$ and retains 2014 Trial and component 1 - absolute media investment.

\section{Conclusion}

The paper investigates how much to invest in media channels and which will be the successful mix in order to obtain a significant higher performance of brand indicators. Moreover, other analyzed area was related to how important is the inherited brand awareness, trial or usage for future brand results.

For Romania, based on over 700 brands monitored, it was noted that specific media channels mix might drive significant different means for the brand indicators. Also, the multiple dimensions of the way that media investment might be analyzed were structured into four important axis based on principal components analysis: media investment in 
absolute measures, main and second proportion in terms of media channel mix, and qualitative aspects of the brand (ad appeal and perceived quality of the brand - absolute level and in dynamics).

For having best results in terms of trial, based on multivariate regression, it is needed to have a consisted brand awareness in the past, specific main proportions of media investment determined by component number 2 (specific media mix and increased budget during the time) and higher absolute media investment. So, the paper reveals that, for boosting brand trial, is important to have past brand awareness inherited, proper media mix adapted to brand specificities and, at last, intensive media investment levels. In that way, the brand may streamline the media investment saving important budgets through smart media mix and gaining similar or better results in brand trial.

For achieving best usage of their brand, it is needed to have inherited a good level of trial and consistent levels of media investment. The study reveals that the funnel brand indicators should be treated in waterfall in order to save budgets and boost results.

As other authors also recommended, for instance Nichols (2013), to continuously evaluate and feed the results back into the model is a very good way to follow. Companies that don't adopt in-depth and well-adapted analytics will be surpassed by those that do. So even if these models are built on a consistent number of brands in Romania, doesn't mean that it might be valid for each brand in any condition. That is why companies must adapt and continuously study their specificities.

\section{References}

Bass, F.M., Bruce, N., Majumdar, S., \& Murthi, B. P. S. (2007). Wearout Effects of Different Advertising Themes: A Dynamic Bayesian Model of the Advertising-Sales Relationship. Marketing Science, volume 26, issue 2. https://doi.org/10.1287/mksc.1060.0208

Dawes, J., Kennedy, R., Green, K., \& Sharp, B. (2018). Forecasting advertising and media effects on sales: Econometrics and alternatives. International Journal of Market Research, Volume: 60 issue: 6, page(s): 611-620.

Dens, N., Pelsmacker, P., Goos, P., Aleksandrovs, L., \& Martens, D. (2018). How consumers' media usage creates synergy in advertising campaigns. International Journal of Market Research, Volume: 60 issue: 3, page(s): 268-287. https://doi.org/10.1177/1470785317751333

Fulgoni, G. (2016). In the Digital World, Not Everything That Can Be Measured Matters. How to Distinguish "Valuable" from "Nice to Know" Among Measures of Consumer Engagement. Journal of Advertising Research. JAR. Page 9. 10.2501/JAR-2016-008.

Gallego, V., Suarez-Garcia, P., Angulo, P., \& Gomez-Ullate, D. (2017). Assessing the effect of advertising expenditures upon sales: a Bayesian structural time series model. Special Issue in Games and Decisions in Reliability and Risk, GDRR 2017.

Nichols, W. (2013). Advertising Analytics 2.0. Harvard Business Review

Nisar, T.M., \& Yeung, M. (2017). Attribution Modeling In Digital Advertising. An Empirical Investigation of the Impact of Digital Sales Channels, Journal of Advertising Research.

Sciarrino, J., Friedman, J., Kirk, T., Kitchings, K. S., \& Prudente, J. (2019). Quantifying the importance, contribution and efficiency of Cotton Inc.'s paid, owned and earned media through customer journey modelling. Henry Stewart Publications.

Yang, S., \& Ghose, A. (2010). Analyzing the Relationship Between Organic and Sponsored Search Advertising: Positive, Negative, or Zero Interdependence? Marketing Science. 29. 602-623. 10.2139/ssrn.1491315. 